\title{
Flow Characteristics Around Step-Up Street Canyons with Various Building Aspect Ratios
}

\author{
Soo-Jin Park ${ }^{1}$ Jae-Jin Kim ${ }^{1}$ - Wonsik Choi ${ }^{1}$ - Eun-Ryoung Kim² ${ }^{2}$ Chang-Keun Song ${ }^{2}$. \\ Eric R. Pardyjak ${ }^{3}$
}

Received: 22 June 2019 / Accepted: 27 November 2019 / Published online: 17 December 2019

(c) The Author(s) 2019

\begin{abstract}
We investigate the flow characteristics around step-up street canyons with various building aspect ratios (ratio of along-canyon building length to street-canyon width, and upwind building height to downwind building height) using a computational fluid dynamics (CFD) model. Simulated results are validated against experimental wind-tunnel results, with the CFD simulations conducted under the same building configurations as those in the windtunnel experiments. The CFD model reproduces the measured in-canyon vortex, rooftop recirculation zone above the downwind building, and stagnation point position reasonably well. We analyze the flow characteristics, focusing on the structural change of the in-canyon flows and the interaction between the in- and around-canyon flows with the increase of building-length ratio. The in-canyon flows undergo development and mature stages as the building-length ratio increases. In the development stage (i.e., small building-length ratios), the position of the primary vortex wanders, and the incoming flow closely follows both the upstream and downstream building sidewalls. As a result, increasing momentum transfer from the upper layer contributes to a momentum increase in the in-canyon region, and the vorticity in the in-canyon region also increases. In the mature stage (i.e., large building-length ratios), the primary vortex stabilizes in position, and the incoming flow no longer follows the building sidewalls. This causes momentum loss through the streetcanyon lateral boundaries. As the building-length ratio increases, momentum transfer from the upper layer slightly decreases, and the reverse flow, updraft, and streamwise flow in the in-canyon region also slightly decrease, resulting in vorticity reduction.
\end{abstract}

Keywords Building-length aspect ratio - Computational fluid dynamics model · Development and mature stages $\cdot$ Flow characteristics $\cdot$ Step-up street canyon

Jae-Jin Kim

jjkim@pknu.ac.kr

1 Department of Environmental Atmospheric Sciences, Pukyong National University, Busan, Korea

2 School of Urban and Environmental Engineering, Ulsan National Institute of Science and Technology, Ulsan, Korea

3 Department of Mechanical Engineering, University of Utah, Salt Lake City, USA 


\section{Introduction}

Urbanization and population growth have increased building density in urban areas, giving rise to various types of morphological features. One of the most representative of these features is the street canyon, which is formed by a road flanked on both sides by buildings. Ensuring a healthy and comfortable atmospheric environment in street canyons has motivated street-canyon flow and dispersion studies (Addepalli and Pardyjak 2013; Wingstedt et al. 2017; Sanchez et al. 2018). Flow and dispersion characteristics in street canyons depend not only on the ambient meteorological conditions but also on the geometric conditions (Assimakopoulos et al. 2003; Balogun et al. 2010; Kellnerová et al. 2014). The effects of ambient meteorological conditions (i.e., ambient winds, turbulence, and atmospheric stability) on flow characteristics in street canyons have been widely investigated using water channels, wind tunnels, and numerical models over the past few decades (Baik et al. 2000; Uehara et al. 2000; Baker et al. 2004; Allegrini et al. 2014; Guillas et al. 2014; Bernardino et al. 2015; Marucci and Carpentieri 2019).

Because building geometries can be diverse and irregular, they can generate complex flow patterns (Aliabadi et al. 2019). Step-up and step-down street canyons, formed by adjacent buildings with different heights flanking a road, are more common than street canyons with buildings of uniform height (i.e., regular or even-notch street canyons) in urban areas. Therefore, studies of the effects of basic, but irregular, building geometries are needed to improve our understanding of urban-flow characteristics. However, most previous studies have focused on idealized geometries, such as even-notch street canyons (Liu et al. 2004; Park and Baik 2012, 2016; Llaguno-Munitxa and Hultmark 2017) and have established the importance of understanding flow characteristics within small urban areas.

Relatively few studies have focused on step-up and/or step-down street canyons (Baik et al. 2000; Sagrado et al. 2002; Huang et al. 2009; Gu et al. 2011; Addepalli and Pardyjak 2013, 2015; Miao et al. 2014; Cui et al. 2016; Hayati et al. 2019). Some examined experimentally and numerically the characteristics of flow and pollutant dispersion in two-dimensional step-up street canyons by comparison with even-notch and step-down street canyons (Baik et al. 2000, Sagrado et al. 2002; Miao et al. 2014). Huang et al. (2009) conducted numerical simulations in two-dimensional step-up and step-down street canyons with wedge-shaped roofs and showed the dependency of the vortices structures and pollutants dispersions on the roof shapes. Gu et al. (2011) showed the dependency of the flow patterns in the step-up and step-down street canyons with the uneven building heights based on large-eddy simulations. Cui et al. (2016) investigated momentum and heat transfer in outdoor and indoor environments around step-up canyons in a stratified flow using windtunnel experiments and a multiscale physical model. They found that the vortex structure and stagnation point in step-up street canyons depend on the Richardson number.

The studies introduced above have contributed to our understanding and insight into the flows and resulting pollutant dispersion in step-up and step-down street canyons. However, the building configurations considered in such studies are two-dimensional or do not reflect the changes in building length in the along-canyon direction. Addepalli and Pardyjak (2013) investigated detailed flow patterns in step-up street canyons with the systematic changes in building length in the along-canyon direction using particle image velocimetry (PIV) in a wind-tunnel facility. They found that the main flow patterns (i.e., recirculations above building roofs and street-canyon vortices) were dependent on the ratio of upwind and downwind building heights. In a follow-up study, Addepalli and Pardyjak (2015) found that topological flow features in step-down street canyons are strongly dependent on the 
building-height ratio. Although the wind-tunnel experiments of Addepalli and Pardyjak $(2013,2015)$ could be utilized as validation results for numerical studies in more realistic building layouts, they have a limitation in providing stereoscopic views for the stepup and step-down street canyon flows. Hayati et al. (2019) validated the step-up and stepdown street-canyon flows simulated by three different computational fluid dynamics (CFD) methods (fast-response mass-conserved semi-empirical, Reynolds-averaged Navier-Stokes equations, and large-eddy simulation solvers) against the high-resolution wind-tunnel data (Addepalli and Pardyjak 2013, 2015), without analyzing three-dimensional flow features in detail.

This study aims to validate flows simulated by a CFD model in step-up street canyons against the Addepalli and Pardyjak (2013) PIV measurements and, based on the CFD simulations through the systematic changes in building height and along-canyon length, to investigate the three-dimensional flow characteristics in step-up street canyons. We suggest the conceptual diagrams of the mean flow patterns generated in step-up street canyons for different building lengths in the along-canyon direction.

\section{Numerical Description}

\subsection{Computational Fluid Dynamics Model}

We use the Kim and Baik (2010) CFD model, which solves the Reynolds-averaged NavierStokes (RANS) equations assuming three-dimensional, non-hydrostatic, nonrotating, and incompressible flow. The governing equations were solved numerically on a staggered grid system using a finite volume method and the semi-implicit method for pressure-linked equations (SIMPLE) algorithm (Patankar 1980). The CFD model employs the power-law differencing scheme (Patankar 1980) and a fully implicit scheme with first-order accuracy for the time integration. Wall boundary conditions suggested by Versteeg and Malalasekera (1995) were implemented to reflect the effects of the turbulent boundary layer properly. The model includes the renormalized group (RNG) $k-\varepsilon$ turbulent closure scheme (Yakhot and Orszag 1986); for further details see Baik et al. (2003) and Kim and Baik (2010).

\subsection{Simulation Set-Up}

The computational domain and building configuration were similar to those in Kim et al. (2015), which focused on the dispersion of pollutants emitted from step-up street canyons with different upwind building heights. We conducted 16 step-up street-canyon simulations with different aspect ratios to examine the CFD model's ability to reproduce the wind-tunnel measurements presented in Addepalli and Pardyjak (2013). Figure 1 shows the model domain configuration. We used the same building configurations as Addepalli and Pardyjak (2013), with fixed street-canyon width $(S=32 \mathrm{~m})$, along-wind building length $\left(L_{a}=32 \mathrm{~m}\right)$, and downwind building height $\left(H_{d}=96 \mathrm{~m}\right)$. The upwind building height $\left(H_{u}\right)$ was set to $32 \mathrm{~m}$ or $57.6 \mathrm{~m}$, and the along-canyon lengths of the buildings $\left(L_{c}\right)$ were systematically varied from 16 to $128 \mathrm{~m}$ in $16-\mathrm{m}$ increments, defining the building-height aspect ratios as $H_{u} / H_{d}=0.33$ and 0.60 (hereafter referred to as shallow and deep street canyons), respectively, and building-length aspect ratios as $L_{c} / S=0.5,1.0,1.5,2.0,2.5,3.0,3.5$, and 4.0, respectively. For comparison, eight additional isolated $96-\mathrm{m}$ tall building simulations were conducted. A 


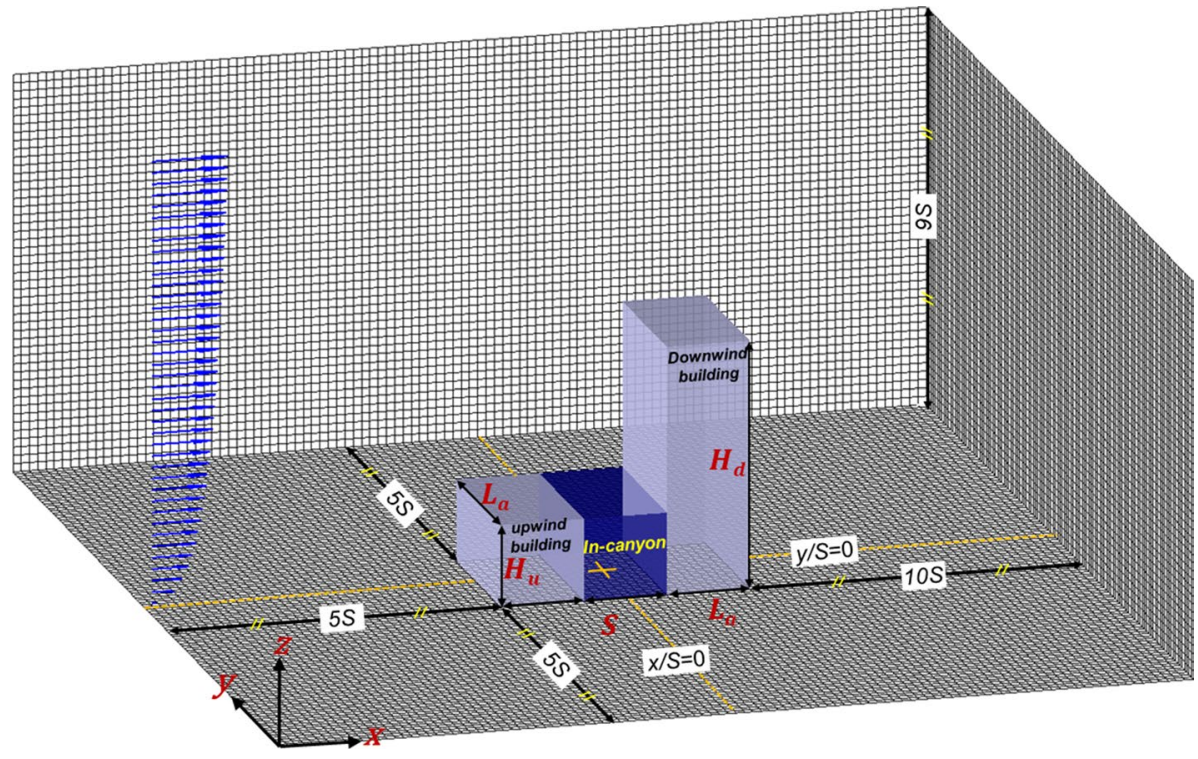

Fig. 1 The building configuration and grid system

uniform grid system with intervals of $3.2 \mathrm{~m}$ in the $x, y$, and $z$ directions was used, with 180 and 90 grid cells in the $x$ and $z$ directions, respectively, and 105-140 grid cells in the $y$ direction, in increments of five grid cells.

The initial conditions for velocity $(U, V, W)$, turbulence kinetic energy $(k)$, and its dissipation rate $(\varepsilon)$ were as specified in Castro and Apsley (1997),

$$
\begin{gathered}
U(z)=U_{d}\left(z / H_{d}\right)^{\alpha}, \\
V(z)=0, \\
W(z)=0, \\
k(z)=\frac{1}{C_{\mu}^{1 / 2}} U_{*}^{2}\left(1-\frac{z}{\delta}\right)^{2}, \\
\varepsilon(z)=\frac{C_{\mu}^{3 / 4} k^{3 / 2}}{\kappa z} .
\end{gathered}
$$

where $\alpha$ is the power-law exponent $(0.21), U_{*}$ is the friction velocity $\left(0.26 \mathrm{~m} \mathrm{~s}^{-1}\right), \delta$ is the boundary-layer depth $(1000 \mathrm{~m}), \kappa$ is the von Kármán constant $(0.4)$, and $C_{\mu}$ is an empirical constant (0.09) in the RNG $k-\varepsilon$ turbulence closure scheme. The mean streamwise wind speed $\left(U_{d}\right)$ at $z=H_{d}$ was $4.32 \mathrm{~m} \mathrm{~s}^{-1}$, giving a Reynolds number based on the downwind building of $2.77 \times 10^{7}$. The CFD model was integrated up to $3600 \mathrm{~s}$ with a timestep of $0.5 \mathrm{~s}$ to establish the mean flow structure for each building configuration. 


\section{Results and Discussion}

\subsection{Comparison of the Simulated Mean Flow Patterns with the Wind-Tunnel Measurement Data}

To examine how well the CFD model reproduces the flow features in step-up street canyons, we first compared the simulated results with Addepalli and Pardyjak's (2013) wind-tunnel data. We performed the simulations in step-up street canyons with building-height ratios $\left(H_{u} / H_{d}\right)$ of 0.33 and 0.60 , respectively, and building-length ratios $\left(L_{c} / S\right)$ of $1,2,3$, and 4 , respectively. Figure 2 shows the measured and simulated streamline fields and distributions of vertical wind component at $y / S=0$ in the shallow street canyons $\left(H_{u} / H_{d}=0.33\right)$. For comparison, the vertical wind component was normalized by the streamwise wind speed at $z=H_{d}\left(U_{d}\right)$. The measured streamlines show the flow passes over the upwind building and affects the downwind building upstream wall, creating a stagnation point (Fig. 2a-d). The flow above the stagnation point separates from the leading edge of the downwind building, resulting in the formation of a rooftop recirculation zone above the downwind building. For all cases, relatively strong downdrafts were induced below the stagnation point in the downwind region of the step-up street canyons (vertical velocities averaged below the stagnation points: $-0.59,-0.73,-0.67$, and $-0.60 \mathrm{~m} \mathrm{~s}^{-1}$ at $L_{c} / S=1,2,3$, and 4 , respectively) and these descending flows contributed to the formation of primary clockwise-rotating vortices in the step-up street canyons. Small counterclockwise-rotating vortices formed in the bottom right-hand corner of the street canyon. Addepalli and Pardyjak (2013) reported that as the building-length aspect ratio increased, the street-canyon vortices became persistent, maintaining a maximum downdraft of $65 \%$ of the streamwise wind speed at the downwind

(a)

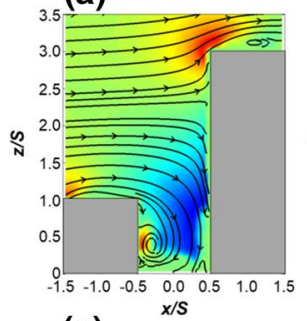

(e)

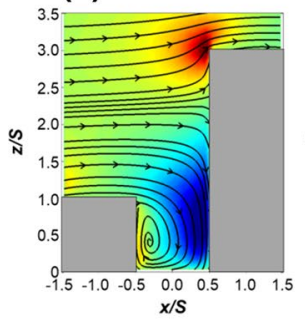

(b)

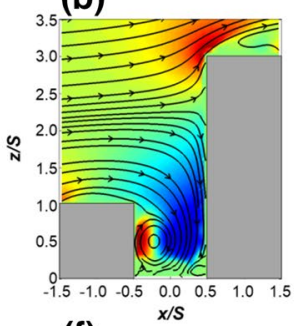

(f)

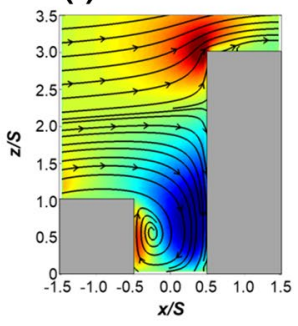

(c)

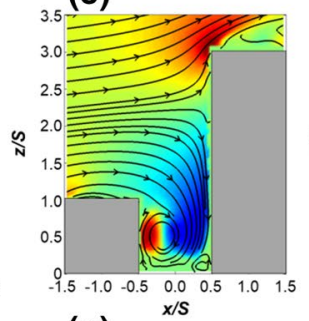

(g)

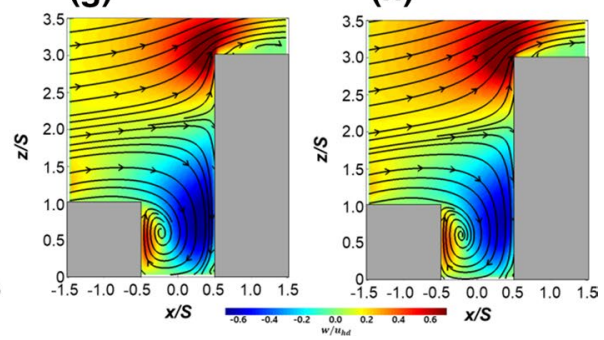

(d)

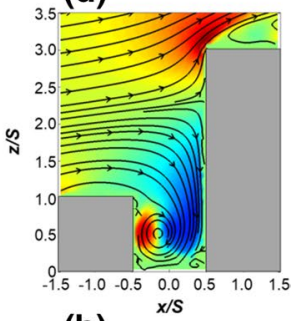

(h)

Fig. 2 Streamlines and contours of the normalized vertical wind component measured by Addepalli and Pardyjak (2013) (upper panels) and simulated in this study (lower panels) in shallow street canyons with building-length ratios $\left(L_{c} / S\right)$ of $1(\mathbf{a}, \mathbf{e}), 2(\mathbf{b}, \mathbf{f}), 3(\mathbf{c}, \mathbf{g})$, and $4(\mathbf{d}, \mathbf{h})$. The vertical wind component is normalized by the streamwise wind speed $\left(U_{d}\right)$ at $z=H_{d}$ 
building height $\left(U_{d}\right)$ (Fig. 2a-d and Table 1). Though the CFD model underestimated the maximum downdrafts and failed to reproduce the small counterclockwise-rotating vortices in the shallow street canyons, it well reproduced the main features such as the clockwiserotating vortices, rooftop recirculation zones above the downwind buildings at lager $L_{c}$ and stagnation-point heights (Fig. 2e-h). The maximum simulated downdrafts were 56\%, 62\%, $57 \%$, and $51 \%$ of $U_{d}$, and the stagnation-point heights $(z / S)$ were $2.3,2.3,2.2$, and 2.2 in the cases of $L_{c} / S=1,2,3$, and 4 , respectively (Table 1 ).

Many previous studies of the two-dimensional (infinitely long) even-notch street canyon have shown that the centre of a roll-type vortex appears near the mid-height but slightly shifts to the downwind direction (Chan et al. 2002; Assimakopoulos et al. 2003; Baik et al. 2012). On the other hand, a portal vortex forms in the three-dimensional (finitely long) even-notch street canyons, and the top part of the portal vortex slants toward the upwind direction (Kim and Baik 2004, 2010; Gowardhan et al. 2011; Michioka et al. 2014). The RANS (Baik et al. 2003) and large-eddy simulations (Michioka et al. 2014) showed that the centre of the portal vortex moved from the upper-height toward mid-height of the street canyon with increasing building length. In the infinitely long even-notch street canyon, the driving force that generates the in-canyon vortex is momentum transfer from the roof-level ambient flow, and only friction slightly decreases the vortex momentum. Consequently, the wind speeds are large in the order of the streamwise, downward, reverse, and upward flows and the vortex centre lies near the street-canyon centre (slightly shifts toward the directions of the downwind building and roof level). As the building length decreases, incoming flows from the lateral boundaries near the downwind building increase and, thus, force the vortex upward and in the upwind direction.

The in-canyon flow feature in the step-up street canyon is different from that in the even-notch street canyon in that the dominant downward flow below the stagnation point displaces the vortex at the vicinity of the upwind building and street bottom. Both in the measurements and simulations, the positions of the vortex centre in the shallow street canyon with $L_{c} / S=1$ are closer to the upwind building and street than those with $L_{c} / S=2,3$, and 4.

In the cases of the deep street canyons, the experimental data indicate that the upstreambuilding rooftop recirculation zones are more extensive than in the shallow street-canyon

Table 1 The measured and simulated maximum downdrafts and stagnation-point heights in the shallow and deep street canyons

\begin{tabular}{|c|c|c|c|c|c|c|c|c|}
\hline \multirow[t]{3}{*}{$L_{\mathrm{c}} / S$} & \multicolumn{4}{|c|}{ Shallow street canyon $\left(H_{d} / H_{u}=0.33\right)$} & \multicolumn{4}{|c|}{ Deep street canyon $\left(H_{d} / H_{u}=0.6\right)$} \\
\hline & \multicolumn{2}{|c|}{$\begin{array}{l}\text { Maximum downdraft } \\
\left(W / U_{d}\right)\end{array}$} & \multicolumn{2}{|c|}{$\begin{array}{l}\text { Stagnation-point height } \\
(z / S)\end{array}$} & \multicolumn{2}{|c|}{$\begin{array}{l}\text { Maximum downdraft } \\
\left(W / U_{d}\right)\end{array}$} & \multicolumn{2}{|c|}{$\begin{array}{l}\text { Stagnation-point height } \\
(z / S)\end{array}$} \\
\hline & Measured & Simulated & Measured & Simulated & Measured & Simulated & Measured & Simulated \\
\hline 0.5 & & -0.44 & & 2.4 & & -0.48 & & 2.6 \\
\hline 1.0 & -0.56 & -0.56 & 2.4 & 2.3 & -0.81 & -0.61 & 2.6 & 2.6 \\
\hline 1.5 & & -0.62 & & 2.3 & & -0.71 & & 2.6 \\
\hline 2.0 & -0.68 & -0.62 & 2.4 & 2.3 & -1.02 & -0.76 & 2.6 & 2.6 \\
\hline 2.5 & & -0.60 & & 2.3 & & -0.75 & & 2.6 \\
\hline 3.0 & -0.66 & -0.57 & 2.3 & 2.2 & -0.71 & -0.75 & 2.6 & 2.6 \\
\hline 3.5 & & -0.53 & & 2.2 & & -0.72 & & 2.6 \\
\hline 4.0 & -0.61 & -0.51 & 2.3 & 2.2 & -0.68 & -0.72 & 2.6 & 2.6 \\
\hline
\end{tabular}


cases, while the rooftop recirculation zones on the downwind building are smaller (Fig. 3a-d). This is because the deep street canyons induce stronger updrafts above the upwind buildings and weaker updrafts above the stagnation points on the downwind buildings. Also, the downdrafts below the stagnation points became stronger than in the shallow step-up street canyons with the same building-length aspect ratio (Table 1). In the incanyon region, the corner vortex, which rotates counterclockwise at the corner between the ground and downwind building, was not present when $L_{c} / S=1$ (Fig. 3a), but it becomes larger as the building-length ratio increases from $L_{c} / S=2-4$ (Fig. 3b-d). The CFD model reproduced the corner vortices with smaller spatial extents than those in the measurements and failed to simulate the recirculation zones measured at $L_{c} / S=1$ and 2 (Fig. 3e-f). The failure in simulating the recirculation zone above the upwind building resulted in flow rather parallel to the roof level above the canyon and wide downward flow under the stagnation point in the in-canyon region. When the building-length ratio is large $\left(L_{c} / S \geq 3\right)$, the maximum downdraft in the CFD simulation is stronger than the measured maximum downdraft (Table 1). This enlarges and intensifies the primary vortex but suppresses the corner vortex in size and intensity. In the absence of upwind buildings, the stagnationpoint heights were lower than those for the step-up street canyons (not shown), indicating that the upwind buildings lifted the stagnation points upward. The stagnation-point height decreased with increasing building-length aspect ratio $\left(L_{c} / S\right)$, which was also measured and simulated in the shallow step-up street canyons (however, constant in the deep step-up street canyons). We also analyzed the stagnation-point heights on the windward face of the upwind buildings (not shown). In spite of the constant stagnation-point height on the windward face of the upwind building $(z / S=0.7$ and 1.2 in the shallow and deep street canyons, respectively), the size of the vortex in front of the upwind building (the so-called horseshoe vortex) increased with increasing building-length aspect ratio (not shown).

As a whole, the measured flow features in the wind-tunnel experiments described above were relatively well simulated by the CFD model. For the deep street canyons, we also summarize the maximum downdrafts and stagnation-point heights in Table 1.

(a)

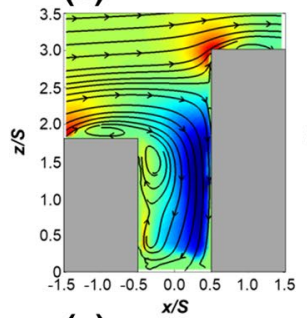

(e)

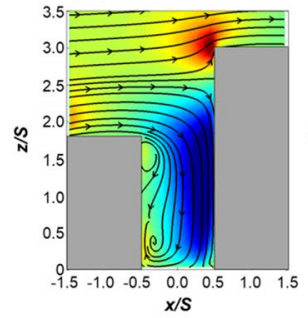

(b)

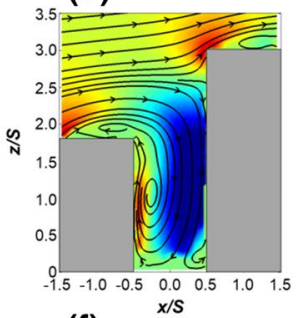

(f)

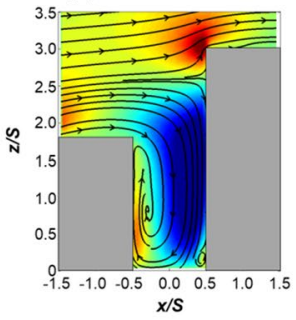

(c)

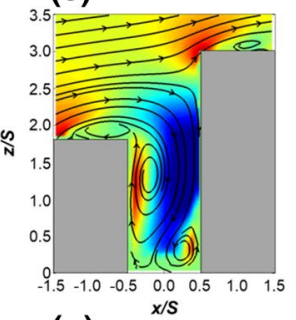

(g)

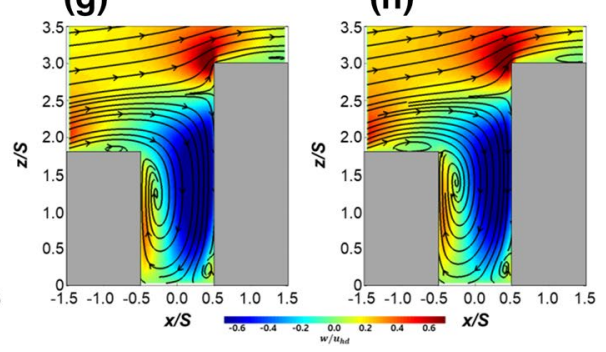

(d)

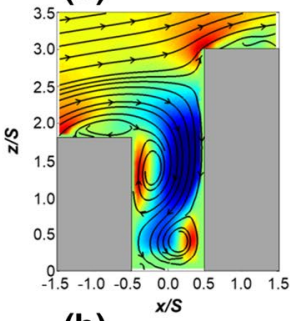

(h)

Fig. 3 The same as Fig. 2, but for deep street canyons 
The stagnation-point heights were perfectly simulated $(z / S=2.6$ in all the cases), but the maximum downdrafts were smaller than in the measurements. The maximum downdraft at $L_{c}=1.0$ and 2.0 are underestimated because the downward motions in the simulations appeared more widely than the measurements in the in-canyon region. Nevertheless, the CFD model reproduced the main flow structures such as in-canyon vortices, rooftop recirculation zones, and stagnation-point heights reasonably well. The magnitude and location of the counterclockwise-rotating vortices could affect the dispersion of pollutants emitted from mobile sources in the street canyon (Cui et al. 2016). For instance, the counterclockwise-rotating vortex residing at the downwind side in the lower layer in this study could block the transport of pollutants toward the upwind side and increase the pollutant concentrations near the centre of the street bottom by making converging zone there (Park et al. 2015).

The CFD model used herein has been extensively validated against the wind-tunnel measurements (Kim and Baik 2004, 2010; Kim 2007; Park et al. 2015, 2016; Kang et al. 2017), giving satisfactory results in simulating flows and pollutant dispersions in evennotch street canyons. However, the CFD model failed to reproduce the other important flow features such as the recirculation zones above the upwind building, corner vortices in the shallow street canyons, and secondary vortices in the deep street canyons. More complex turbulence patterns in the step-up street canyons emerge compared to the even-notch street canyons, which might have become a problem for the turbulence scheme used.

\subsection{Schematic Views of the Main Flow Patterns}

In this section, we analyze the main flow features, focusing on the development of the incanyon flow and the interaction between the in-canyon flow and the outer flow with the increase of the building-length ratio. The in-canyon flows simulated in the shallow and deep street canyons underwent two stages (i.e., development and mature stages) as the building-length ratio increased. The schematics of the flow patterns for the two stages were drawn for the shallow and deep step-up street canyons (Figs. 4, 7), mainly based on the numerical simulations.

\subsubsection{Development Stage}

The mean flows enter the development stage in both the shallow and deep street canyons for small building-length ratios $\left(L_{c} / S \lesssim 2\right)$. This street canyon represents two isolated buildings with a short length in succession. At this stage, the shape of the primary vortex mimics a portal (hereafter denoted as a portal vortex) (Fig. 4a). A portal vortex is symmetric around $y / S=0$ (Becker et al. 2002; Tominaga and Stathopoulos 2016), its central axis is tilted toward the upwind building, and the height of the central axis decreases toward the lateral boundaries of the street canyon. To understand the main flow structures around the street canyons in detail, we searched for the centres of the in-canyon vortices and rooftop recirculation zones and the centres of the side-wall recirculation zones by calculating the vorticity magnitudes at each $x-z$ cross-section $(|(\partial U / \partial z-\partial W / \partial x)|)$ and $x-y$ cross-section $(|(\partial V / \partial x-\partial U / \partial y)|)$, respectively (Fig. 5). As the building-length ratio $\left(L_{c} / S\right)$ increases from 0.5 to 2 , the central axis of the portal vortex moves upward (Fig. 5a-d). Outward motions toward the lateral boundaries on both sides of the street canyon are dominant near the street bottom (Fig. 6a). On the other hand, in the mid-layer and upper layer, inward 

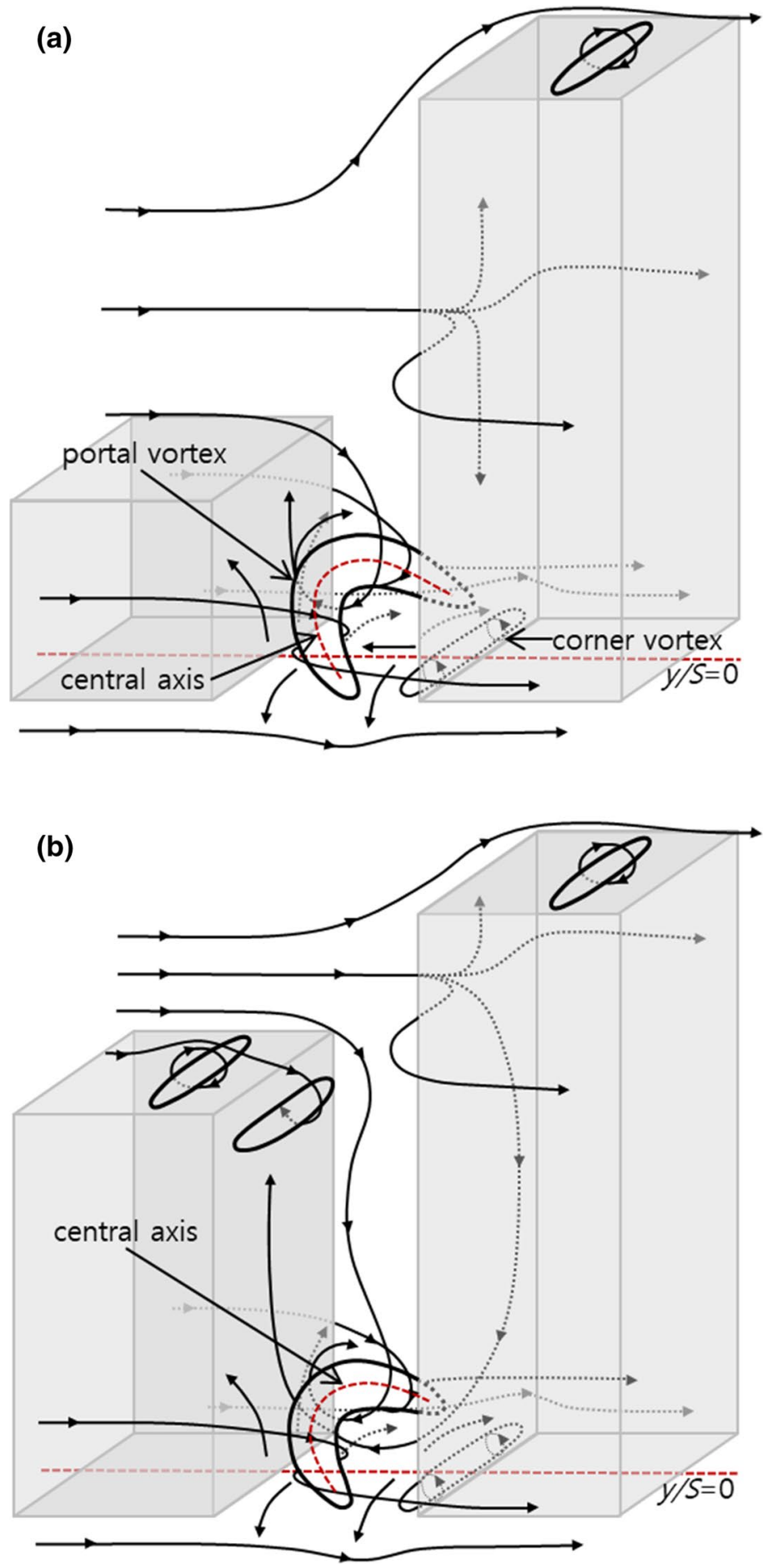

Fig. 4 The schematics of the mean flow circulation for the development stage $\left(L_{c} / S \lesssim 2\right)$ in the, a shallow step-up, and $\mathbf{b}$ deep step-up street canyons 


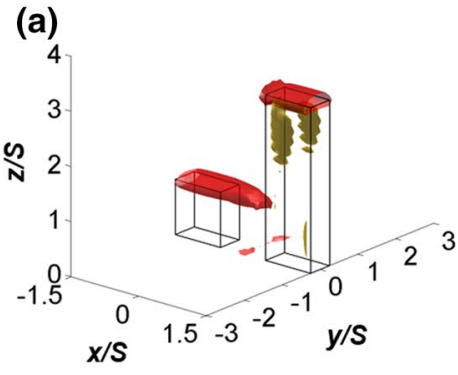

(c)

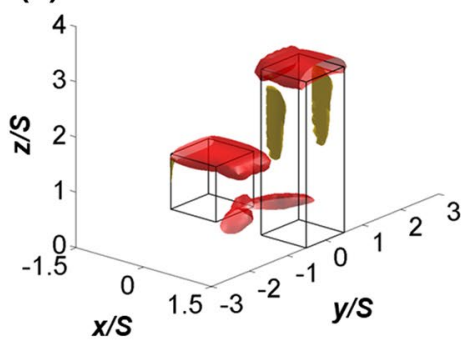

(e)

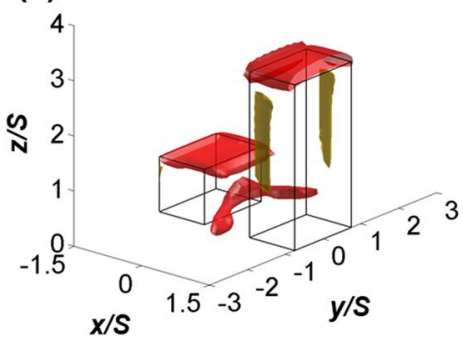

(g)

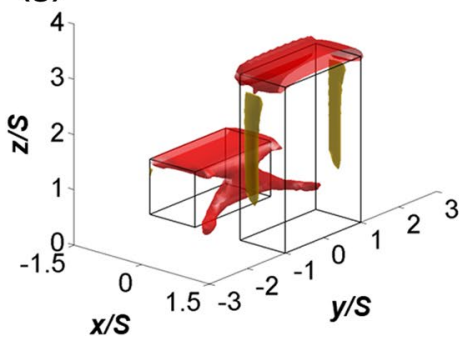

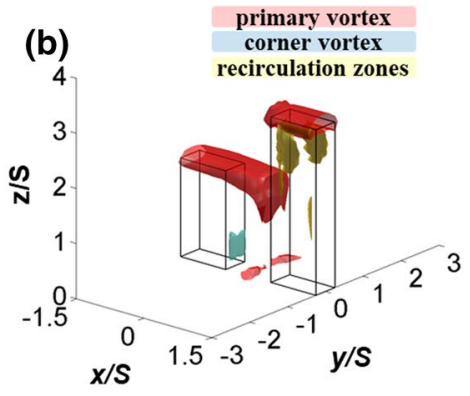

(d)

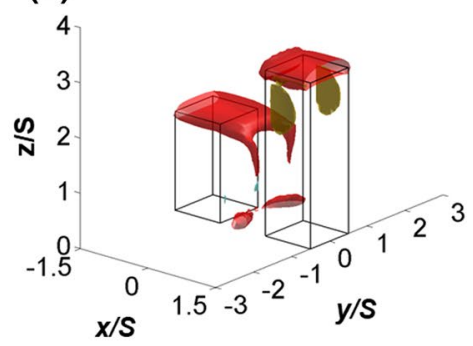

(f)

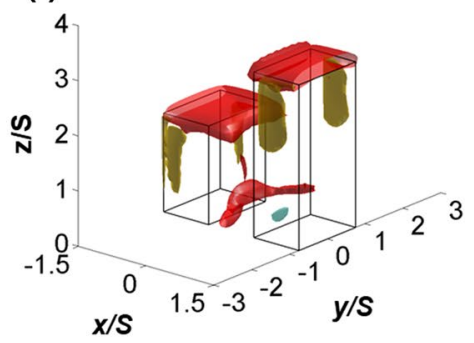

(h)

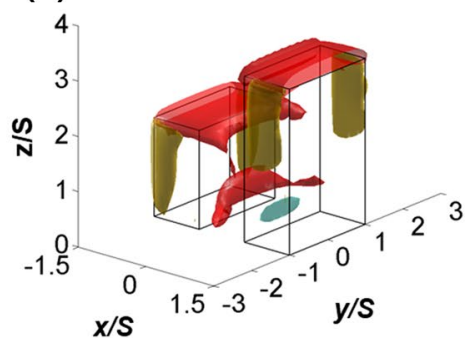

Fig. 5 The recirculation zones and in-canyon vortices captured from the simulated results in the shallow (left panels) and deep step-up street canyons (right panels) in the cases of $L_{c} / S=0.5(\mathbf{a}, \mathbf{b}), 1.0(\mathbf{c}, \mathbf{d}), 1.5$ (e, f), and $2.0(\mathbf{g}, \mathbf{h})$

motions are dominant rather than the outward motions, except near the downwind building (Fig. 6c, e). 
(a)

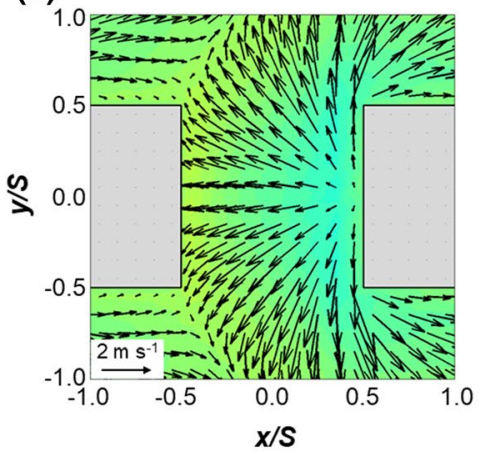

(c)

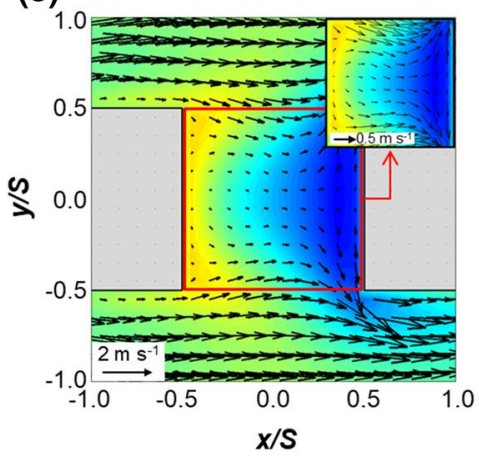

(e)

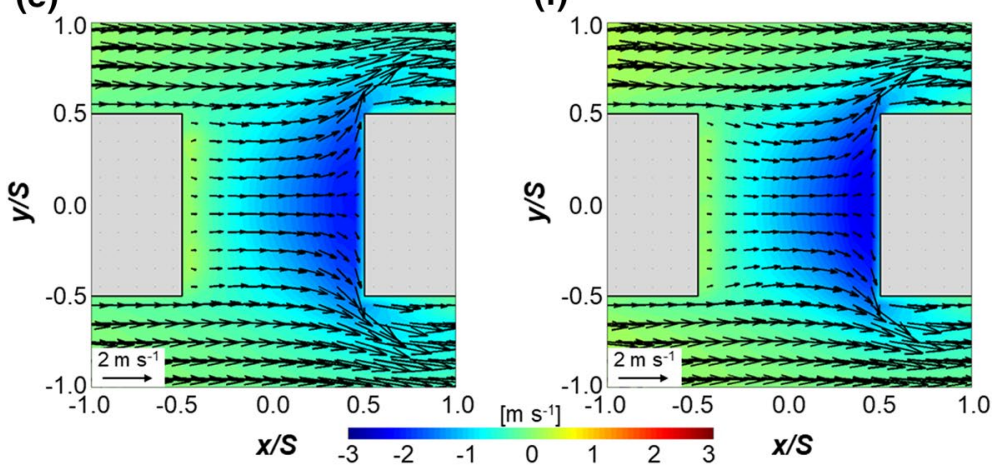

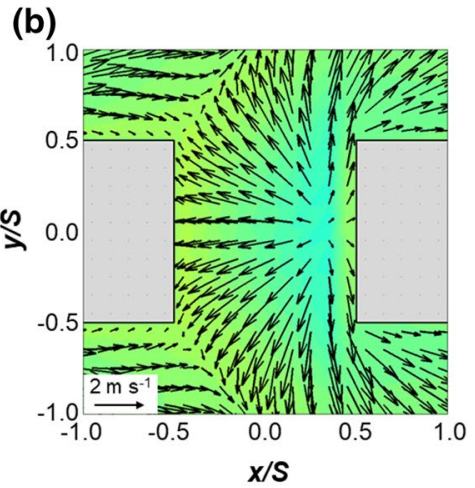

(d)

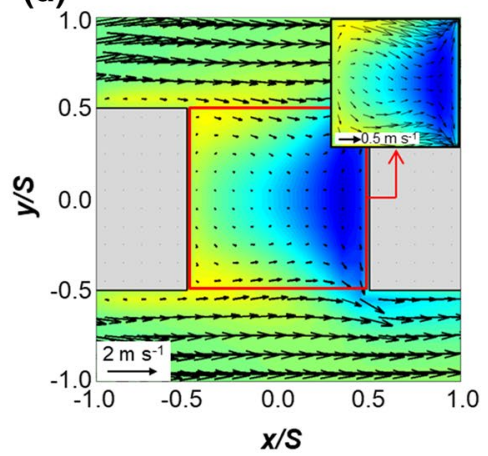

(f)

Fig. 6 Wind vectors and contours of the vertical wind component at $z / H_{u}=0.05(\mathbf{a}, \mathbf{b}), 0.45(\mathbf{c}, \mathbf{d})$, and 0.9 $(\mathbf{e}, \mathbf{f})$ in the shallow (left panels) and deep step-up street canyons (right panels) with $L_{c} / S=1.0$

The main characteristics of the mean flow in the deep step-up street canyons are almost like those in the shallow step-up street canyons, except for the size of the secondary vortex in the corner between the downwind building and the street bottom (hereafter denoted as the corner vortex) (Figs. 4b, 5b, d, f, h, 6b, d, f). The corner vortex rotates in the opposite direction of the primary vortex. The CFD model resolved the corner vortex 

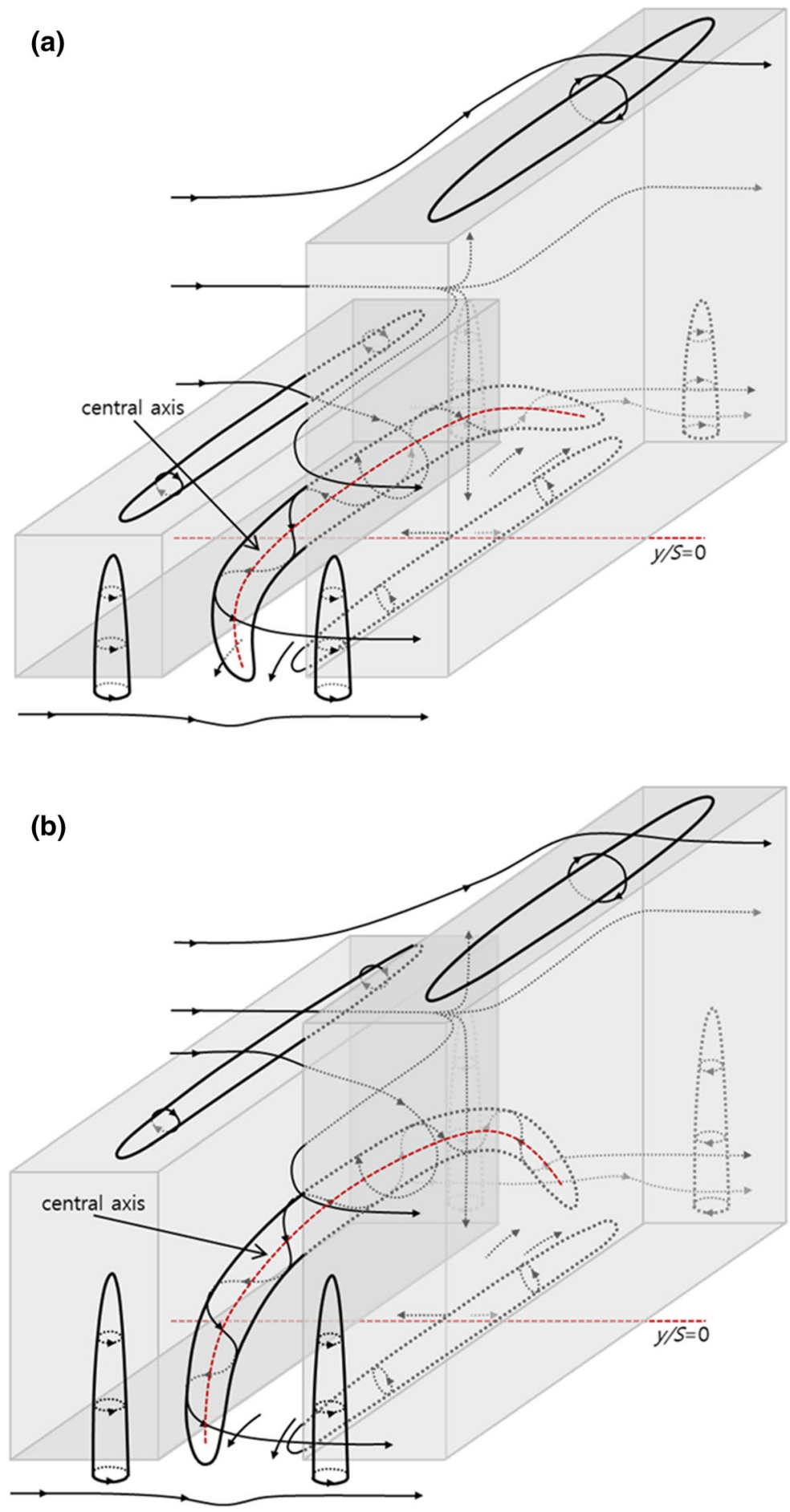

Fig. 7 The same as Fig. 4, but for the mature stage $\left(L_{c} / S \gtrsim 2\right)$ 
but could not resolve the growth of the corner vortex (i.e., it underestimated the size of the corner vortex).

\subsubsection{Mature Stage}

When the building-length ratio is large $\left(L_{c} / S \gtrsim 2\right)$, the mean flow reaches the "mature" stage. The main features of the mean flow in the mature stage are like those in the development stage, except for two differences: (i) the generation of the side-wall recirculation zones, and (ii) the appearance of straight central axes in the portal vortices (Fig. 7). In the mature stage, two side-wall recirculation zones are generated on both sides of the upwind and downwind buildings (Figs. 8, 9). Flow coming towards an obstacle separates at the sharp upwind lateral edges of the obstacle. One part of the flow crosses over the obstacle, and the other part makes a detour around both sides of the obstacle (Tominaga and Stathopoulos 2016). In the mature stage, relatively long buildings induce strong outward flows in both spanwise directions near the side edges of the upwind building, resulting in flow separation causing the side-wall recirculation zones (Fig. 9).

Similarly, two side-wall recirculation zones along the downwind building are generated by the strong outward flows along the windward wall of the downwind building (Fig. 9). Note that no inward flow appears along the lateral boundaries of the street canyons in the mature stage, while weak inward flow appears at the mid-height of the street canyon during the development stage (Fig. 6c, d). Besides, the height variations of the location of the central axes are tiny in the middle of the street canyon, but the central axes slightly inclined near both lateral boundaries of the street canyon as in the development stage (Fig. 8). Even though the building-length ratio increased $\left(L_{c} / S \gtrsim 2\right)$, the flat part of the central axis had no significant change in height and position (Fig. 8 and Table 1). It implies that the mean incanyon flow becomes fully developed for $L_{c} / S \gtrsim 2$.

The mean flow in the deep step-up street canyon had no marked difference from those in the shallow step-up street canyon, as in the development stage. The in-canyon flows are induced mainly by the incoming flows from the roof level of the street canyons interacting with the flows along the lateral boundaries of the street canyon. When the building-length ratio is small (i.e., the development stage), the outward motions of the in-canyon flow are not strong enough to overcome the inward motions from outside the street canyon, except near the street bottom (Figs. 6, 10). As the building-length ratio increases, the outward (inward) motions become strong (weak), and the primary vortices become stabilized in position (Fig. 5). The central axes of the portal vortices are located at a constant height (Fig. 6), and only the outward motions appear along the lateral boundaries of the street canyons (Figs. 9, 10).

A recirculation zone was generated behind the downwind building. As the buildinglength aspect ratio increases, the recirculation zone grows, and its centre moves far downstream of the downwind building (not shown). This is because the reattachment of flows crossing over and detouring around an obstacle converge farther downstream with increasing building length.

\subsection{Further Analysis of the In- and Around-Canyon Flow Characteristics}

The in-canyon flows simulated by the CFD model underwent two stages (development and mature) with increasing building-length ratios. In this section, we further analyze the in-canyon flow characteristics as well as the relationships between the changing trends 
(a)

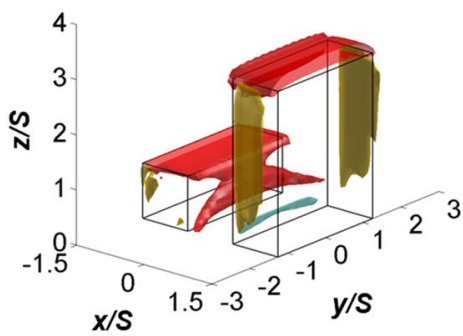

(c)

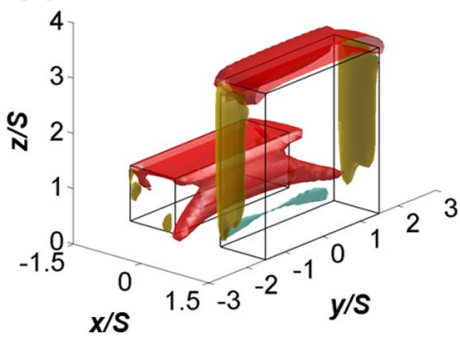

(e)

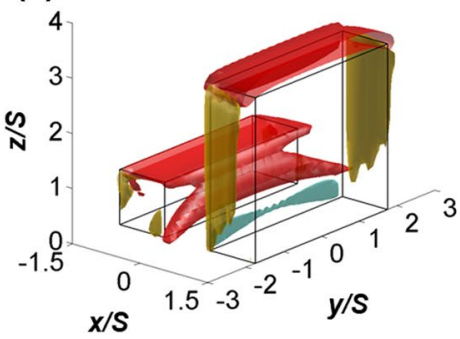

(g)

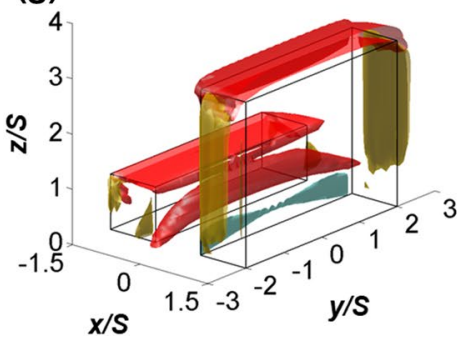

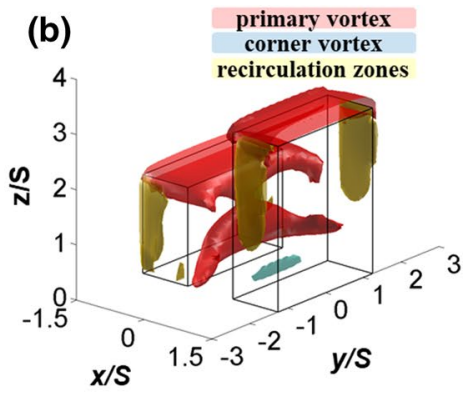

(d)

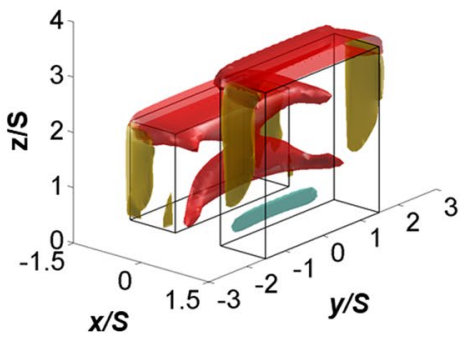

(f)

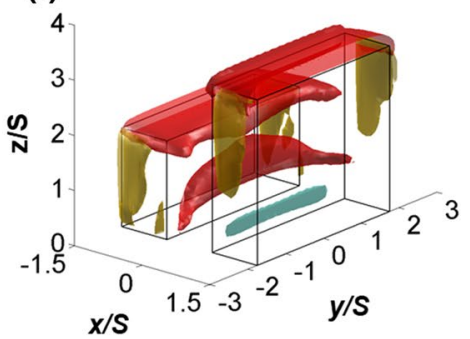

(h)

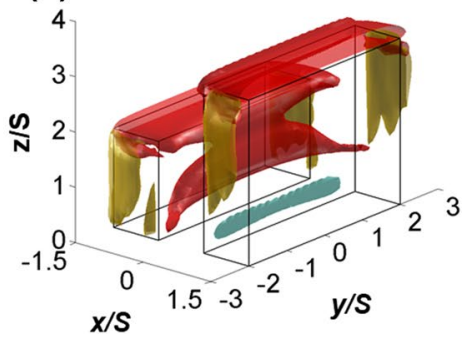

Fig. 8 The recirculation zones and in-canyon vortices captured from the simulated results in the shallow (left panels) and deep step-up street canyons (right panels) in the cases of $L_{c} / S=2.5$ (a, b), 3.0 (c, d), 3.5 (e, f), and $4.0(\mathbf{g}, \mathbf{h})$

of the vorticity fluxes and the flow stages. The vorticity in the along-canyon direction $(\omega=\partial U / \partial z-\partial W / \partial x)$ was calculated at each grid point of $y / S=0$ within the in-canyon region $\omega_{i}=(\partial U / \partial z-\partial W / \partial x)$ and then averaged over the in-canyon region. The results are compared with Addepalli and Pardyjak's (2013) measurement results. For comparison, 
(a)

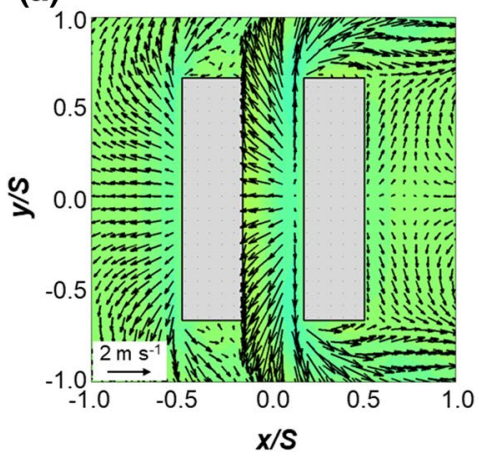

(c)

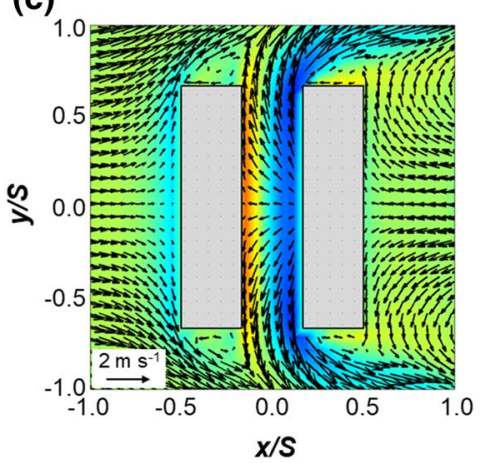

(e)

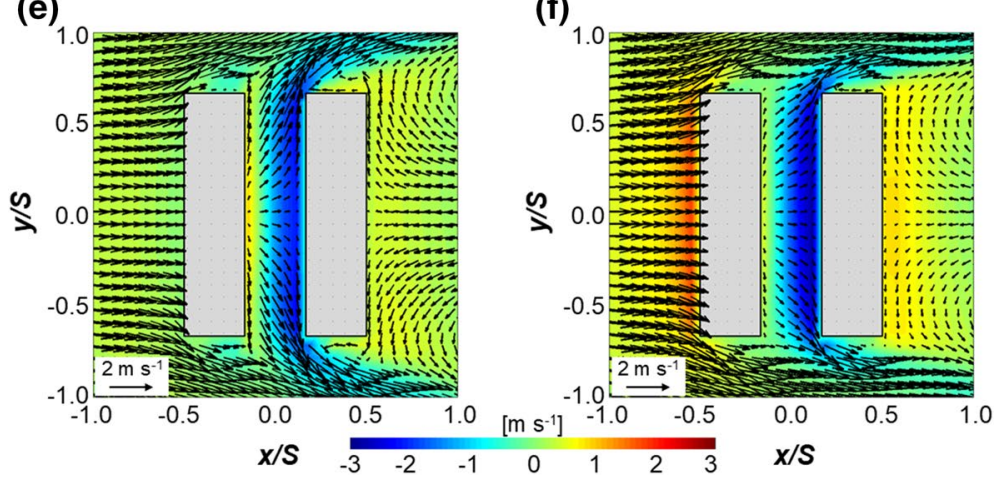

(b)

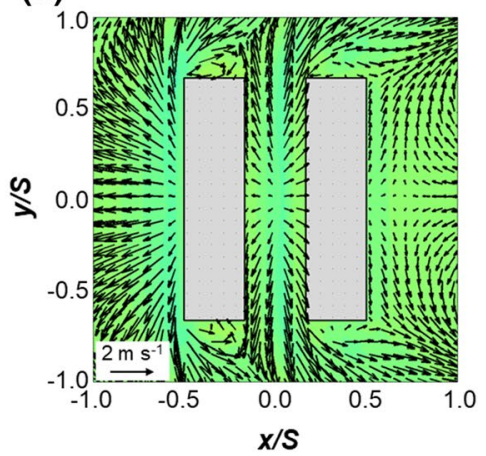

(d)

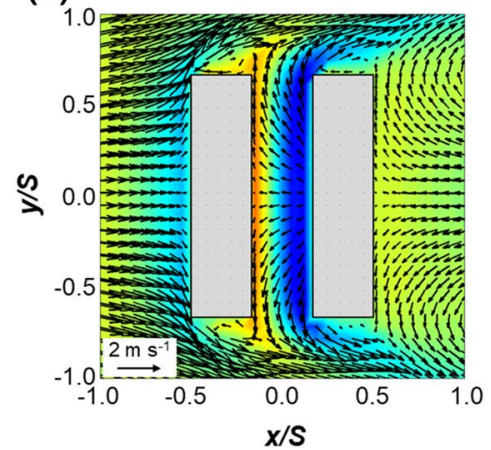

(f)

Fig. 9 Wind vectors and contours of the vertical wind component at $z / H_{u}=0.05(\mathbf{a}, \mathbf{d}), 0.45(\mathbf{b}, \mathbf{e})$, and 0.9 $(\mathbf{c}, \mathbf{f})$ in the shallow (left panels) and deep step-up street canyons (right panels) with $L_{c} / S=4.0$

the averaged vorticities were normalized by the maximum vorticities $\left(\omega_{\max }\right)$ at $L_{c} / S=2$. Note that the maximum vorticities in the wind-tunnel experiments also occurred at $L_{c} / S=2$. Figure 11 shows the normalized vorticity $\left(\omega_{n}=\omega / \omega_{\max }\right)$. The CFD simulations overestimated the normalized vorticities at large $L_{c} / S$ values in both the shallow and deep street canyons. Addepalli and Pardyjak (2013) argued that the decrease of the net circulation with building-length ratio resulted from the vorticity offsetting between the primary and secondary (corner) vortices. The larger overestimations at $L_{c} / S=3.0$ and 4.0 in the deep street 
(a)

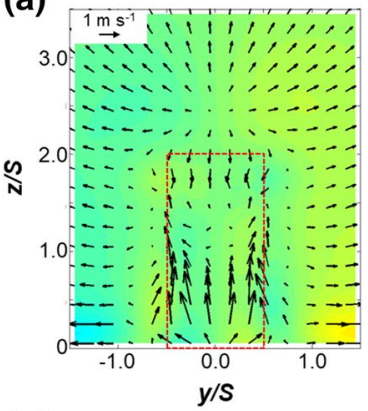

(c)

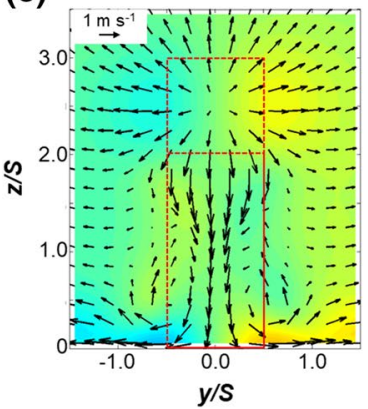

(e)

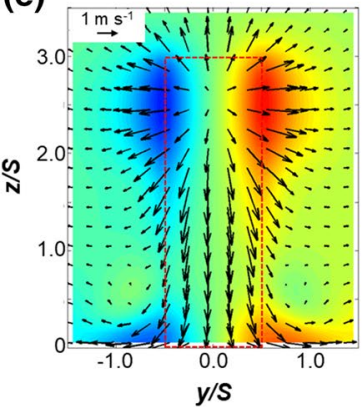

(b)

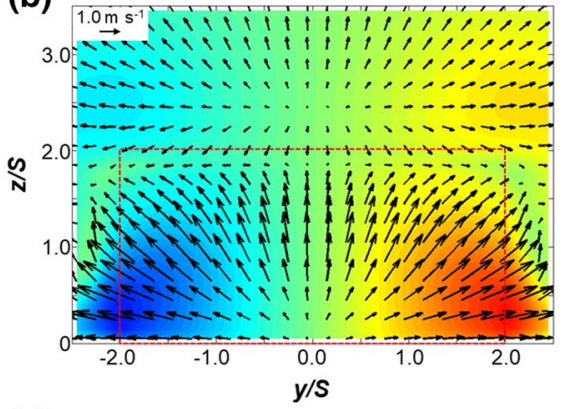

(d)

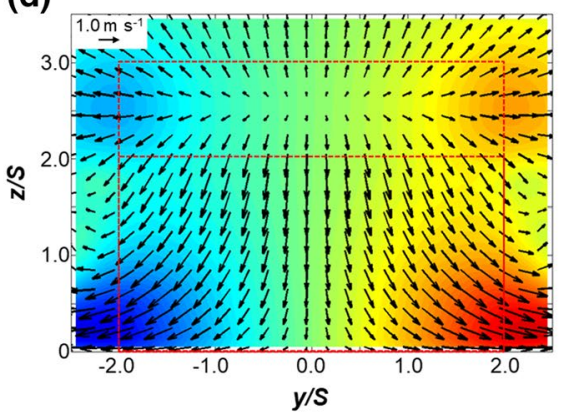

(f)

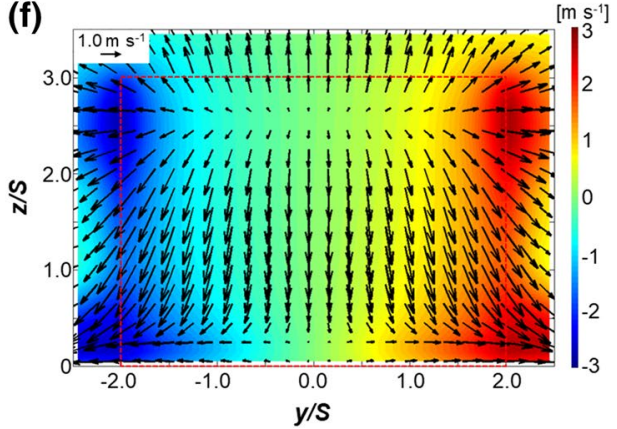

Fig. 10 Wind vectors and contours of the $V$ component at $x / S=-0.45(\mathbf{a}, \mathbf{b}), 0.0(\mathbf{c}, \mathbf{d})$, and $0.45(\mathbf{e}, \mathbf{f})$ in the deep step-up street canyon with $L_{c} / S=1.0$ (left panels) and 4.0 (right panels)

canyons resulted from an underestimation of the size of the secondary vortex, which has opposite-sign vorticity compared to the primary vortex (Fig. 3). However, the simulated trend of vorticity with the building-length ratio is similar to the wind-tunnel measurements. That is, the vorticity is maximum at $L_{c} / S=2$ and then decreases with increasing buildinglength ratio, similar to the trend in the maximum downdraft in Table 1.

We further investigated the variation of the flow components averaged over the in-canyon regions with increasing building-length ratio based on the simulated results. For simplicity, we averaged the velocity components [i.e., $U>0$ (streamwise flow), $U<0$ (reverse flow), $W>0$ (updraft), and $W<0$ (downdraft)] in the in-canyon region. Although the trends of each velocity component did not vary monotonically, they were similar to the average vorticity in Fig. 11, except that the maximum values occurred at slightly different buildinglength ratios and the streamwise flow at small building-length ratios were larger (Fig. 12). 
Fig. 11 The averages of the normalized vorticity in the shallow and deep street canyons

Fig. 12 The changes in magnitude of the downdraft, reverse flow, updraft, streamwise flow, and outward flow averaged over the in-canyon region with the building-length ratio in the, a shallow, and b deep step-up street canyons

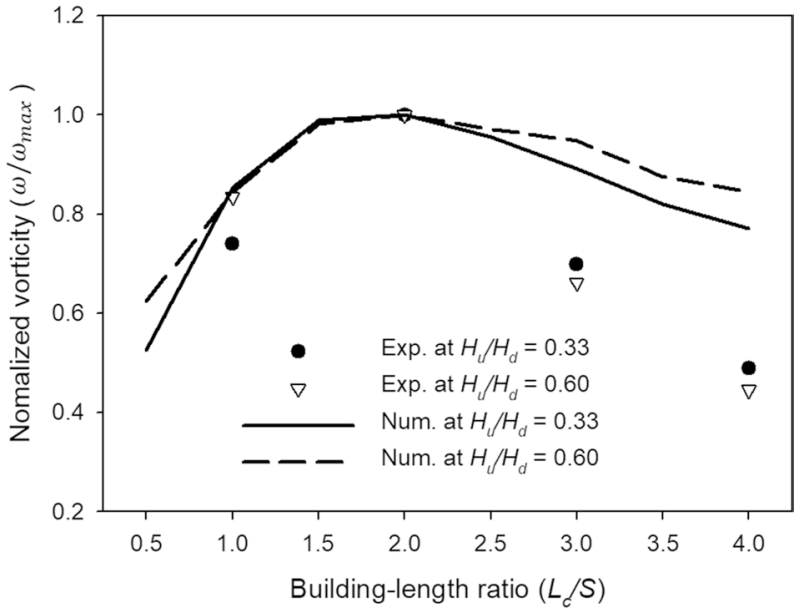

(a)

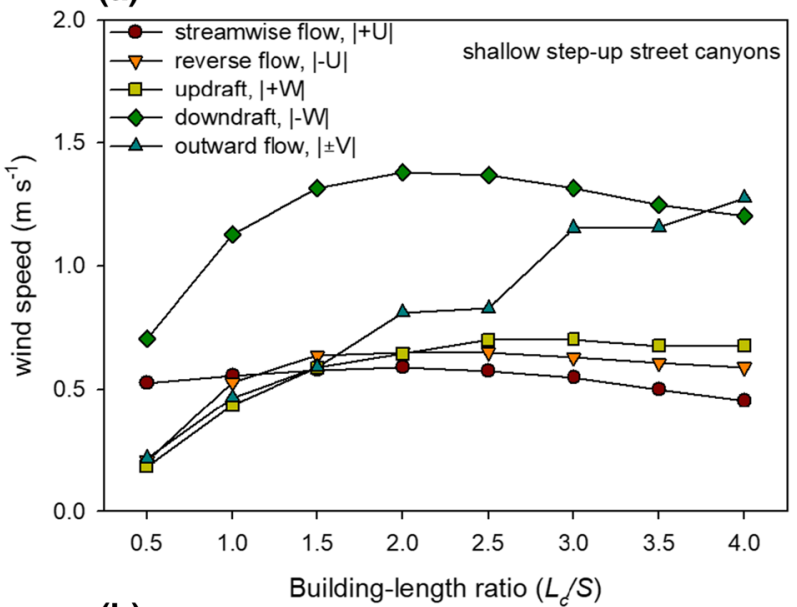

(b)

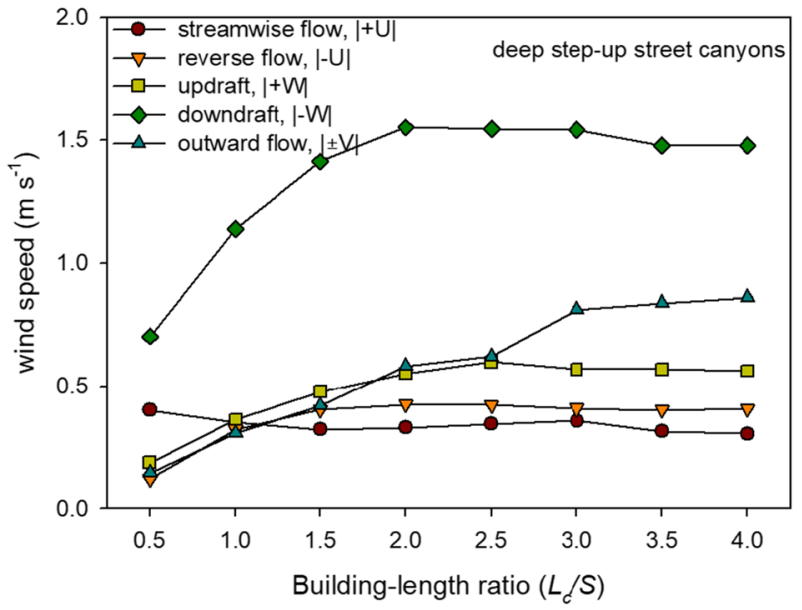


On the other hand, the outward flow ( $V<0$ for $y / S<0$ and $V>0$ for $y / S>0$ ) became stronger as the building-length ratio increased. The change rates of the downdraft, reverse flow, updraft, and streamwise flow at large $L_{c} / S$ values was smaller than those at small $L_{\mathrm{c}} / S$ values. This is because the in-canyon flows become stabilized at large $L_{c} / S$ values (mature stage).

By comprehensively taking the results for the in- and around-canyon flows into account, the flow characteristics around the step-up street canyons are summarized as follows: at small $L_{c} / S$ values (development stage), the incoming flow closely follows the side-walls along the upwind and downwind buildings of the street canyon without generating sidewall recirculation zones. This is due to the relatively weak flows in the spanwise direction along the upwind wall of the upwind building and the consequent weak flow separations at the leading edges of the upwind building. Further, inward flows are dominant at the lateral boundaries of the street canyons. As the building length increases, the downdraft under the stagnation point on the downwind building wall becomes stronger with little momentum loss through the lateral boundaries of the street canyons due to the airflow outside of the canyon wrapping around its lateral edges. Consequently, the reverse flows $(U<0)$, updrafts $(W>0)$, and streamwise flows $(U>0)$ increase in the in-canyon region, which is considered the main reason for the vorticity increase with increasing building-length ratios.

As the building-length ratio increases, at large $L_{c} / S$ values (mature stage), the spanwise flows along the upwind wall of the upwind building become strong, while the incoming flows above the upwind building weaken. Strong separation occurs at the upwind building edges and the flow no longer follows the building sides walls closely. As a result, an outward flow dominates along the lateral boundaries of the street canyon. The downdraft in the canyon slightly decreases, followed by a slight decrease in the reverse flow, updraft, and streamwise flow (i.e., reduced circulation in the canyon). It is concluded that this trend causes a slight decrease in vorticity according to the increase of the building-length ratio at large $L_{c} / S$ values (mature stage).

\section{Summary and Conclusions}

We investigated the flow characteristics for step-up street canyons with fixed street-canyon width $(S)$ and downwind building height $\left(H_{d}\right)$, but varying along-canyon building length $\left(L_{c}\right)$ and upwind building height $\left(H_{u}\right)$, using an RNG $k-\varepsilon$ computational fluid dynamics (CFD) model. The building-height ratios $\left(H_{u} / H_{d}\right)$ considered were 0.33 and 0.60 (shallow and deep street canyons, respectively), with the building-length ratio $\left(L_{c} / S\right)$ ranging from 0.5 to 4.0 with an increment of 0.5 . Simulated results were validated against previous experimental results performed for the same building configurations but for four buildinglength ratios $\left(L_{c} / S=1,2,3\right.$, and 4$)$. We conclude that, although the CFD model underestimates the sizes of the corner vortices near the ground in the deep street canyons, it reproduces the main flow features measured in the wind-tunnel experiments well, such as the street-canyon vortices, circulations above the building roof, maximum downdrafts, and the positions of the stagnation points.

We analyzed the flow characteristics, focusing on the growth of the in-canyon flow and the interaction between the in- and around-canyon flows with increasing building-length ratios. The results showed that the in-canyon flows experience two stages (development and mature) as the building-length ratio increased. Schematics of the flow patterns that occur during the development and mature stages were drawn for the shallow and deep 
step-up street canyons. In the development stage, the primary vortex with the shape of a portal (portal vortex) was not stable (i.e., the vortex central axis wandered with increasing building-length ratio). The main structure of the mean flows in the deep step-up street canyon was similar to that in the shallow step-up street canyon, except for the size of the secondary (corner) vortex. The incoming flow closely follows the lateral building side walls. As a result, increasing momentum transfer from the upper layer contributes to a momentum increase in the in-canyon region and a consequent vorticity increase. During the mature stage, the main features of the mean flow were similar to the development stage, except for two features: (1) side recirculation zones were generated, and (2) the central axis of the primary vortex was maintained almost flat in the middle of the street canyon despite the increasing building-length ratio. The primary vortex stabilized in one position and the incoming flow no longer followed the building side walls. This caused momentum losses through the lateral boundaries of the street canyons. As the building-length ratio increased, momentum transfer from the upper layer slightly decreased and the reverse flow, updraft, and streamwise flow in the in-canyon region also slightly decreased, resulting in vorticity reduction. Further analysis showed that the vorticity in the in-canyon was maximized at $L_{c} / S=2$ (boundary between the development and mature stages), and then slightly decreased with increasing building-length ratios. The trend of the downdraft, reverse flow, updraft, and streamwise flow averaged over the in-canyon region was similar to that of the vorticity.

Most previous studies have focused on rather ideal building configurations, providing insight and improvement of our understandings of street-canyon flows and dispersions. The building configurations (step-up street canyons) considered in this study are more common in real urban areas but are still simplified. We hope the results in this study will provide basic concepts for understanding the complicated flows in real urban areas and give an implication for the design of numerical simulations in idealized building geometries. Shortly, we will also investigate the flow characteristics in the step-down street canyon with the extensive validation of PIV measurements.

Acknowledgements This work was funded by the Korea Meteorological Administration Research and Development Program under Grants 'KMI2018-06610' and 'KMI2017-02410'.

Open Access This article is licensed under a Creative Commons Attribution 4.0 International License, which permits use, sharing, adaptation, distribution and reproduction in any medium or format, as long as you give appropriate credit to the original author(s) and the source, provide a link to the Creative Commons licence, and indicate if changes were made.The images or other third party material in this article are included in the article's Creative Commons licence, unless indicated otherwise in a credit line to the material. If material is not included in the article's Creative Commons licence and your intended use is not permitted by statutory regulation or exceeds the permitted use, you will need to obtain permission directly from the copyright holder.To view a copy of this licence, visit http://creativecommons.org/licenses/by/4.0/.

\section{References}

Addepalli B, Pardyjak ER (2013) Investigation of the flow structure in step-up street canyons-mean flow and turbulence statistics. Boundary-Layer Meteorol 148:133-155

Addepalli B, Pardyjak ER (2015) A study of flow fields in step-down street cantons. Environ Fluid Mech 15:439-481

Aliabadi AA, Moradi M, Clement D, Lubitz WD, Gharabaghi B (2019) Flow and temperature dynamics in an urban canyon under a comprehensive set of wind directions, wind speeds, and thermal stability conditionsA study of flow fields in step-down street cantons. Environ Fluid Mech 19:81-109 
Allegrini J, Dorer V, Carmeliet J (2014) Buoyant flows in street canyons: validation of CFD simulations with wind tunnel measurements. Build Environ 72:63-74

Assimakopoulos VD, ApSimon HM, Moussiopoulos N (2003) A numerical study of atmospheric pollutant dispersion in different two-dimensional street canyon configurations. Atmos Environ 37:4037-4049

Baik J-J, Park R-S, Chun H-Y, Kim J-J (2000) A laboratory model of urban street-canyon flows. J Appl Meteorol 39:1592-1600

Baik J-J, Kim J-J, Fernando JS (2003) A CFD model for simulating urban flow and dispersion. J Appl Meteorol 42:1636-1648

Baik J-J, Kwak K-H, Park S-B, Ryu Y-H (2012) Effects of building roof greening on air quality in street canyons. Atmos Environ 61:48-55

Baker J, Walker HL, Cai X (2004) A study of the dispersion and transport of reactive pollutants in and above street canyons-a large eddy simulation. Atmos Environ 38:6883-6892

Balogun AA, Tomlin AS, Wood CR, Barlow JF, Belcher SE, Smalley RJ, Lingard JJN, Arnold SJ, Dobre A, Robins AG, Martin D, Shallcross DE (2010) In-street wind direction variability in the vicinity of a busy intersection in central London. Boundary-Layer Meteorol 136:489-513

Becker S, Lienhart H, Durst F (2002) Flow around three-dimensional obstacles in boundary layers. J Wind Eng Ind Aerodyn 90:265-279

Bernardino AD, Monti P, Leuzzi G, Querzoli G (2015) Water-channel study of flow and turbulence past a two-dimensional array of obstacles. Boundary-Layer Meteorol 155:73-85

Castro IP, Apsley DD (1997) Flow and dispersion over topography: a comparison between numerical and laboratory data for two-dimensional flow. Atmos Environ 31:850-893

Chan TL, Dong G, Leung CW, Cheung CS, Hung WT (2002) Validation of a twodimensional pollutant dispersion model in an isolated street canyon. Atmos Environ 36:861-872

Cui PY, Li Z, Tao WQ (2016) Wind-tunnel measurements for thermal effects on the flow and pollutant dispersion through different scale urban areas. Build Environ 97:137-151

Gowardhan AA, Pardyjak ER, Senocak I, Brown M (2011) A CFD-based wind solver for an urban fast response transport and dispersion model. Environ Fluid Mech 11:439-464

Gu ZL, Zhang YW, Cheng Y, Lee SC (2011) Effect of uneven building layout on air flow and pollutant dispersion in non-uniform street canyons. Build Environ 46:2657-2665

Guillas S, Glover N, Malki-Epshetein L (2014) Bayesian calibration of the constants of the $k-\varepsilon$ turbulence model for a CFD model of street canyon flow. Comput Methods Appl Mech Eng 279:536-553

Hayati AN, Stoll R, Pardyjak ER, Harman T, Kim J-J (2019) Comparative metrics for computational approaches in non-uniform street-canyon flows. Build Environ 158:16-27

Huang Y, Hu X, Zeng N (2009) Impact of wedge-shaped roofs on airflow and pollutant dispersion inside urban street canyon. Build Environ 44:2335-2347

Kang G, Kim J-J, Kim D-J, Choi WS, Park S-J (2017) Development of a computational fluid dynamics model with tree drag parameterizations: Application to pedestrian wind comfort in an urban area. Build Environ 124:209-218

Kellnerová R, Kukačka L, Jurčáková K, Uruba V, Jaňour Z (2014) PIV measurement of turbulent flow within a street canyon: detection of coherent motion. J Wind Eng Ind Aerodyn 104-106:302-313

Kim (2007) The Effects of Obstacle Aspect Ratio on Surrounding Flows. Atmosphere 17:381-391 (with English Abstract)

Kim J-J, Baik J-J (2004) A numerical study of the effects of ambient wind direction on flow and dispersion in urban street canyons using the RNG $k-e$ turbulence model. Atmos Environ 38:3039-3048

Kim J-J, Baik J-J (2010) Effects of street-bottom and building-roof heating on flow in three-dimensional street canyons. Adv Atmos Sci 27:513-527

Kim ER, Park RJ, Lee DG, Kim JJ (2015) A study on the characteristics of flow and reactive pollutants' dispersion in step-up street canyon using a CFD model (with English Abstract). Atmosphere 25:473-482

Liu CH, Barth MC, Leung DYC (2004) Large-eddy simulation of flow and pollutant transport in street canyons of different building-height-to-street-width ratios. J Appl Meteorol 43:1410-1424

Llaguno-Munitxa B-ZE, Hultmark M (2017) The influence of building geometry on street canyon air flow: validation of large eddy simulations against wind tunnel experiments. J Wind Eng Ind Aerodyn 165:115-130

Marucci D, Carpentieri M (2019) Effect of local and upwind stratification on flow and dispersion inside and above a bi-dimensional street canyon. Build Environ 156:74-88

Miao Y, Liu S, Zheng Y, Wang S, Li Y (2014) Numerical study of traffic pollutant dispersion within different street canyon configurations. Adv in Meteorol 2014:1-14

Michioka T, Takimoto H, Sato A (2014) Large-Eddy simulation of pollutant removal from a three-dimensional street canyon. Boundary-Layer Meteorol 150:259-275 
Park S-B, Baik J-J (2012) A large-eddy simulation study of thermal effects on turbulent flow and dispersion. J Appl Meteorol Climatol 51:829-841

Park S-J, Kim J-J, Kim M-J, Park R-J, Cheong H-B (2015) Effects of building-roof cooling on the flow and dispersion of reactive pollutants in an idealized urban street canyon. Atmos Environ 108:20-31

Park S-J, Choi W, Kim J-J, Kim MJ, Park RJ, Han KS, Kang G (2016) Effects of building-roof cooling on the flow and dispersion of reactive pollutants in an idealized urban street canyon. Build Environ 109:175-189

Patankar SV (1980) Numerical heat transfer and fluid flow. McGraw-Hill, New York, pp 126-131

Sagrado APG, van Beecl J, Rambaud P, Olivari D (2002) Numerical and experimental modelling of pollutant dispersion in a street canyon. J Wind Eng Ind Aerodyn 90:321-339

Sanchez B, Santiago JL, Martilli A, Martin F, Borge R, Quaassdorff C, Paz DDL (2018) Modeling NOx concentrations through CFD-RANS in an urban hot-spot using high resolution traffic emissions and meteorology from a mesoscale model. Atmos Environ 163:155-165

Tominaga Y, Stathopoulos T (2016) Ten questions concerning modeling of near-filed pollutant dispersion in the built environment. Build Environ 105:390-402

Uehara K, Murakami S, Oikawa S, Wakwmatsu S (2000) Wind tunnel experiments on how thermal stratification affects flow in and above urban street canyons. Atmos Environ 34:1553-1562

Versteeg HK, Malalasekera W (1995) An introduction to computational fluid dynamics: the finite volume method. Longman, Kuala Lumpur, pp 198-203

Wingstedt EMM, Osnesn AN, Akervik E, Eriksson D, Reif BAP (2017) Large-eddy simulation of dense gas dispersion over a simplified urban. Atmos Environ 152:605-616

Yakhot V, Orszag SA (1986) Renormalization group analysis of turbulence. J Sci Comput 1:3-51

Publisher's Note Springer Nature remains neutral with regard to jurisdictional claims in published maps and institutional affiliations. 